\title{
Congenital heart defects in children with cleft lips and/or palates at an academic hospital in central South Africa
}

\author{
WJ Barrett ${ }^{1}$, BJS Diedericks' ${ }^{1}$ (D, CL Barrett ${ }^{2}$ (D), G Joubert ${ }^{3}$, EW Turton ${ }^{1 *}$ \\ 1 Department of Anaesthesiology, \\ ${ }^{2}$ Department of Internal Medicine, \\ ${ }^{3}$ Department of Biostatistics, \\ Faculty of Health Sciences, University of the Free State, Bloemfontein, South Africa \\ *Corresponding author, email: turtonew@ufs.ac.za; edwinturton@mweb.co.za
}

Background: Globally, cleft deformities are the most common craniofacial anomalies and show an association with congenital heart defects. Little research on cleft lips and/or palates (CL/P) and congenital heart defects has been reported from Africa, and none from South Africa. In 2001, it was proposed that CL/P be listed as one of six priority conditions for monitoring and notification to South African health authorities. This goal of creating a national registry has not been achieved. A near-fatal anaesthetic incident following a missed cardiac lesion in a child with a cleft lip and palate prompted this study.

Objectives: To describe the prevalence of congenital heart defects diagnosed in children with CL/P presenting for corrective surgery during the Smile Week over three consecutive years (2013-2015) at an academic hospital in South Africa.

Methods: A retrospective, descriptive file review of 62 patients with CL/P was performed. Since 2013, echocardiography has been performed on all patients with $\mathrm{CL} / \mathrm{P}$.

Results: Twenty-three, 21 and 18 patients were operated in 2013, 2014 and 2015, respectively. Of these patients, $85.5 \%(n=53)$ had no clinical evidence of a cardiac defect, of which eight did have clinically significant cardiac defects on echocardiography. Sixteen patients $(25.8 \%)$ in total $(n=16 / 62)$ with a cleft deformity had a clinically significant congenital heart lesion. Of the 16 patients with a cardiac defect on transthoracic echocardiography, only four had clinical evidence of cardiac defect. Therefore, sensitivity of clinical examination was $25 \%$, whereas the specificity was $89.1 \%$. Three of the four patients with a syndrome had a clinically significant echocardiographic finding.

Conclusion: A national guideline for the preoperative care of patients with $\mathrm{CL} / \mathrm{P}$, including routine echocardiography, is needed. Furthermore, a national registry is required for patients with $\mathrm{CL} / \mathrm{P}$ with associated congenital anomalies.

Keywords: congenital heart defects, cleft deformities, cleft lip, cleft palate, cleft lip with or without cleft palate

\section{Introduction}

The Smile Foundation, a South African non-profit organisation (NPO number 063/498 and PBO number 930/030/006), assists children with cleft lips and/or cleft palates who are in need of reconstructive surgery. Surgery is offered at eight academic hospitals throughout the country. Furthermore, the Smile Foundation supports public healthcare facilities by purchasing medical equipment, upgrading of facilities and sponsorship of academic programmes for the medical team involved.

The Department of Plastic and Reconstructive Surgery at Universitas Academic Hospital (UAH) in Bloemfontein, South Africa, has a dedicated cleft deformity clinic, where patients are screened and selected for corrective surgery. UAH hosts the Bloemfontein Smile Week annually in September. Corrective cleft surgery is performed on approximately five patients per day (20 patients per Smile Week).

During the UAH Smile Week of 2011, a 12-year-old female patient was booked for a cleft palate (CP) repair. Preoperatively, she had no clinical signs of cyanosis, murmur or cardiac pathology. During corrective cleft palate surgery, her intra- and postoperative course was complicated by a clinically significant severe right-to-left shunt. This prompted the performance of a transthoracic echocardiogram (TTE) in the recovery room by the anaesthetic team, followed by a formal TTE by a paediatric cardiologist. A Tetralogy of Fallot (TOF) was diagnosed, which was corrected six weeks later by means of open heart surgery. Had the TOF been diagnosed preoperatively, the repair of the congenital heart defect (CHD) would have taken priority over the surgery for the cleft palate repair. This adverse event raised the question whether a TTE should be performed as routine preoperative evaluation of patients with cleft lip and/or cleft palate deformities. We therefore reviewed our experience over a three-year period.

The aim of the study was to investigate the prevalence of congenital heart defects diagnosed in children with cleft lips and/or palates presenting for corrective surgery at the Smile Weeks of 2013, 2014 and 2015, at Universitas Academic Hospital in Bloemfontein, South Africa. Since 2013, echocardiography has 
been performed on all patients with $\mathrm{CL} / \mathrm{P}$ presenting for Smile Week at UAH.

\section{Methods}

A retrospective descriptive file review was performed at a single academic institution. The principal researcher (WJB) reviewed the theatre lists of patients booked by the Department of Plastic and Reconstructive Surgery during the Smile Weeks of 2013-2015. All files were drawn from medical records and patients who met the required criteria were included in the study. The inclusion and exclusion criteria were as follows:

\section{Inclusion criteria}

- Admission during the Smile Weeks of 2013-2015 for corrective cleft surgery;

- Admission at UAH, Department of Plastic and Reconstructive Surgery, for corrective cleft surgery;

- Patients with cleft lip, cleft palate or cleft lip and cleft palate;

- Patients with significant cardiac defects requiring cancellation of surgery.

\section{Exclusion criteria}

- Previous inclusion in the study;

- Admission for surgery other than cleft surgery;

- Patients cancelled for anaesthesia on preoperative assessment for reasons other than congenital heart defects, e.g. respiratory tract infection.

Patient files from Plastic Surgery, Paediatric Cardiology, Paediatrics, Human Genetics and Anaesthetics charts were reviewed. Every effort was made to trace records from all departments to ensure quality of data. The following data were collected on the data sheet: date of birth, date of surgery, gender, ethnicity, type of cleft deformity, history of cardiac defect and intervention (if appropriate), dysmorphisms and syndromes, clinical evidence of cardiac defects, and echocardiographic and theatre reports where applicable. Specific red flags in the perioperative assessment were noted, namely clinical evidence of heart defect (abnormal cardiac examination), dysmorphic features and documented echocardiographic cardiac defect. Symptoms enquired about when taking the patient's history were related to recurrent chest infections, fatigue, cyanosis and poor feeding. Cardiac examination involved obtaining evidence of a heart murmur, loud second heart sound, cyanosis and clinical signs of pulmonary overflow.

The definition of cleft deformities is inconsistent, with the only clear definition occurring in a World Health Organization (WHO) document.' For the purposes of this article, a cleft lip (CL) with or without cleft palate (CL/P) refers to a congenital malformation characterised by partial or complete clefting of the upper lip with or without clefting of the alveolar ridge or the hard palate. It excludes midline cleft of the upper or lower lip and oblique facial fissure. Various processes that build up the face are involved in the non-fusion of the cleft of the lip. Cleft lip, which includes the alveolar processes and the palate, is known as a cleft lip and palate (CLP). Clefts may be unilateral, usually on the left side, or bilateral. A cleft palate without cleft lip (CP) refers to a congenital malformation characterised by a closure defect of the hard and/or soft palate behind the foramen incisivium without a cleft lip. CP includes submucus cleft palate. ' Figure 1 represents the classification of cleft deformities. It should be noted that inconsistencies in the definitions have made interpretation of the literature challenging, as different authors use the terminology interchangeably.

\begin{tabular}{|l|l|l|l|l|l|l|}
\hline Classification & Definition & Deformity & Cleft lip \\
palate: oral cleft & without cleft palate
\end{tabular}

Figure 1. Classification of cleft deformities. 
No pilot study was performed. An informal study was performed at the same institution in 2012 (ethics approval reference number ECUFS 180/2012). The findings of this study were presented at the Paediatric Anaesthesia Congress of South Africa (PACSA) in 2012. At this congress, the question pertaining to the performance of transthoracic echocardiography as routine preoperative workup for patients with cleft deformities at UAH, was raised. Since 2013, echocardiography is performed preoperatively on all patients with clefts.

Results were summarised by frequencies and percentages (categorical variables) and means and standard deviations or percentiles (numerical variables). Cleft deformity groups were compared using chi-squared tests or Fisher's exact tests for categorical variables and Kruskall-Wallis tests for numerical variables.

The Free State Province Department of Health and the Ethics Committee of the University of the Free State (ECUFS 111/2016) approved the protocol for the study. Heads of the following clinical units gave consent for access to patient records: Anaesthesiology, Plastic and Reconstructive Surgery, Paediatric Cardiology, Paediatrics and Human Genetics. Patients' confidentiality was maintained by using a unique study number for each case.

\section{Results}

Seventy-one files were screened for inclusion for the study. Nine files were excluded due to not meeting the inclusion criteria, giving a total of 62 patients whose data were analysed. Twentythree, 21 and 18 patients were operated in 2013, 2014 and 2015, respectively. Patient selection is summarised in Figure 2, and the patient demographics in Table I.

Patients were divided into three groups on the type of cleft deformity, namely cleft lip (CL), cleft palate (CP) and CLP (cleft lip and palate). In all three groups, female patients were the majority $(p=0.18)$. No statistically significant difference regarding race was found between the groups $(p=0.32)$. The median age of all the patients was 2.8 years (range $0.43-13.23$ years). Patients with $\mathrm{CL}$ were significantly younger than the other two groups $(p=0.01)$. The youngest age of surgery for CLP was 22.4 weeks. Figure 3 displays the age of children at the time of surgery.

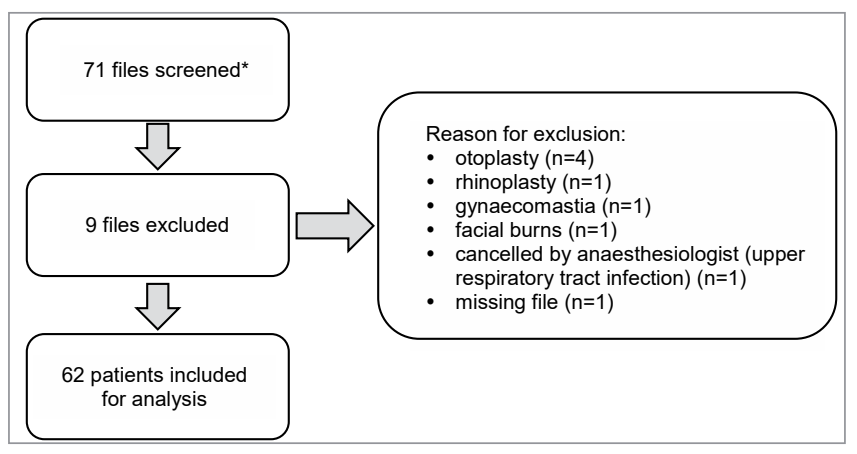

Figure 2. Selection of patient files for inclusion in the study. ${ }^{*}$ Any patient who presented for repeat surgery during the Smile Weeks of 2013-2105, kept their original file and patient number. The data for patients presented for repeat surgery were only captured once.

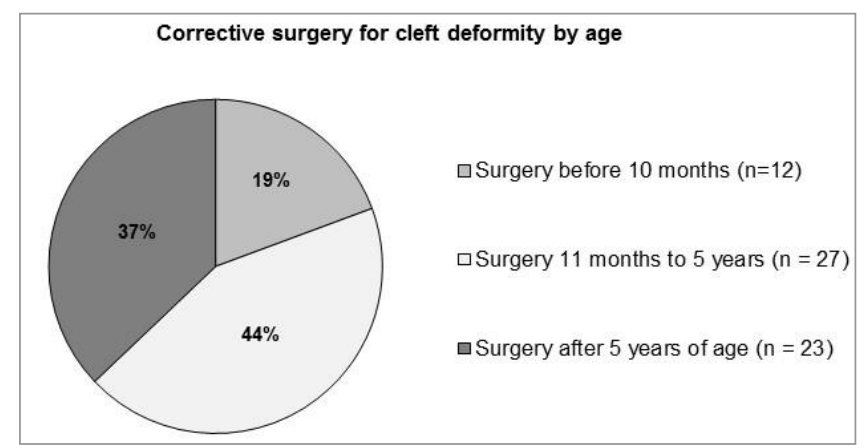

Figure 3. Age of patients by the time of undergoing corrective surgery. No surgery was performed on patients younger than 10 weeks.

Patients' pre- and postoperative cardiac data are summarised in Table II. Sixteen patients (25.8\%) had clinically significant echocardiographic cardiac defects. Of these patients, only four had clinical evidence of cardiac defect on physical examination (three patients had cardiac murmurs and one had clinical signs of pulmonary overflow on respiratory system examination), giving a sensitivity of clinical examination of $25 \%$, compared to the specificity of $89.1 \%$. Fifty-three patients ( $85.5 \%$ ) had no clinical evidence of a cardiac defect. However, eight of these patients did have clinically significant cardiac defects found on echocardiography. Three of the four patients with a syndrome had a clinically significant echocardiographic finding. No cyanosis was detected in any of the patients.

Table I. Demographic information of patients with cleft deformaties

\begin{tabular}{|c|c|c|c|c|}
\hline \multirow{2}{*}{ Variable } & \multicolumn{3}{|c|}{ Type of cleft deformity } & \multirow{2}{*}{ Total $(n=62)$} \\
\hline & $C L(n=14)$ & $\operatorname{CLP}(n=25)$ & $C P(n=23)$ & \\
\hline $\begin{array}{l}\text { Median age in years } \\
\text { (interquartile range; IQR) }\end{array}$ & $\begin{array}{c}0.84 \\
(0.55-2.14)\end{array}$ & $\begin{array}{c}4.16 \\
(1.28-7.51)\end{array}$ & $\begin{array}{c}4.12 \\
(1.71-7.15)\end{array}$ & $\begin{array}{c}2.8 \\
(1.00-7.15)\end{array}$ \\
\hline \multicolumn{5}{|l|}{ Gender } \\
\hline Male n (\%) & $2(14.3)$ & $9(36.0)$ & $10(43.5)$ & $21(33.9)$ \\
\hline \multicolumn{5}{|l|}{ Ethnicity } \\
\hline Black n (\%) & $13(92.9)$ & $19(76.0)$ & $14(60.9)$ & $46(74.2)$ \\
\hline White n (\%) & $1(7.1)$ & $4(16.0)$ & $7(30.4)$ & $12(19.4)$ \\
\hline Mixed race n (\%) & $0(0)$ & $2(8.0)$ & $2(8.7)$ & $4(6.5)$ \\
\hline
\end{tabular}

CL: cleft lip; CLP: cleft lip and palate; CP: cleft palate; IQR: interquartile range. 
Table II. Clinical data of patients with cleft deformities $(n=62)$.

\begin{tabular}{|c|c|}
\hline Clinical data & n (\%) \\
\hline \multicolumn{2}{|l|}{ History of cardiac defect } \\
\hline No & $53(85.5)$ \\
\hline Normal transthoracic echocardiography (TTE) & $45(72.6)$ \\
\hline $\begin{array}{l}\text { New diagnosis of clinically significant cardiac defect } \\
\text { on TTE }\end{array}$ & $8(12.9)$ \\
\hline Yes & $9(14.5)^{\mathrm{a}}$ \\
\hline \multicolumn{2}{|l|}{ Clinical evidence of cardiac defect } \\
\hline No & $53(85.5)$ \\
\hline Yes & $9(14.5)$ \\
\hline \multicolumn{2}{|l|}{ Dysmorphic features } \\
\hline No & $44(71.0)$ \\
\hline Yes & $18(29.0)$ \\
\hline \multicolumn{2}{|l|}{ Documented syndrome } \\
\hline No & $58(93.5)$ \\
\hline Yes & $4(6.5)$ \\
\hline Pierre Robin sequence & 2 \\
\hline Dyskinetic cerebral palsy & 1 \\
\hline Orocraniofacial syndrome & 1 \\
\hline \multicolumn{2}{|l|}{ Preoperative cardiogram performed } \\
\hline No & $0(0)$ \\
\hline Yes & $62(100)$ \\
\hline \multicolumn{2}{|l|}{ Clinically significant cardiac defects present on TTE } \\
\hline No & $46(74.2)$ \\
\hline Yes $^{b}$ & $16(25.8)$ \\
\hline Ventricular septal defect (VSD) & $3(4.8)$ \\
\hline Patent ductus arteriosus (PDA) & $0(0)$ \\
\hline Perforated foramen ovale (PFO) & $8(12.9)$ \\
\hline Atrial septal defect (ASD) & $2(3.2)$ \\
\hline Atrioventricular septal defect (AVSD) & $0(0)$ \\
\hline Pulmonary hypertension (PHPT) $)^{c}$ & $7(11.3)$ \\
\hline Peripheral pulmonary stenosis & $5(8.1)$ \\
\hline $\begin{array}{l}\text { Bicuspid aortic valve and azygous continuation of } \\
\text { inferior vena cava (IVC) }\end{array}$ & $1(1.6)$ \\
\hline Enlarged right atrium & $1(1.6)$ \\
\hline $\begin{array}{l}\text { Aneurysmal intra-atrial septum with tricuspid } \\
\text { insufficiency }(\mathrm{TI}) \text { and pulmonary incompetence }(\mathrm{PI})\end{array}$ & $1(1.6)$ \\
\hline Abnormal intraoperative ECG & $1(1.6)$ \\
\hline Intraoperative right-to-left shunt ${ }^{\mathrm{e}}$ & $2(3.2)$ \\
\hline Number of surgically corrected cardiac defects ${ }^{f}$ & $1(1.6)$ \\
\hline
\end{tabular}

a One of the nine patients had a non-clinically significant heart defect on echocardiography (TI, PI).

b Of note, among these 16 patients, a total of 28 cardiac lesions were identified. Only four of these patients had clinical evidence of cardiac defect.

c Pulmonary hypertension was noted in addition to the primary cardiac lesion

d Sick sinus syndrome with irregularly-irregular pulse.

e Both these patients had a PFO.

${ }^{f}$ Cardiac defects corrected prior to cleft surgery included VSD, PDA, bicuspid aorta, abnormal IVC, PHPT.

Table III shows the congenital cardiac anomalies found on echocardiography according to cleft deformity. Eighteen patients $(29.0 \%)$ with a cleft deformity had a dysmorphism that was not part of a syndrome, eight of whom had cleft lips, five had cleft lip and palate, and five had cleft palate only. No statistically significant relationship between dysmorphic features and congenital heart lesions was found. Four patients had a syndrome, three of whom had an associated congenital heart defect diagnosed on echocardiography. The cardiac lesions that were most commonly diagnosed were PFO, VSD and ASD.

\section{Discussion}

This study conducted at the Universitas Academic Hospital (UAH) in Bloemfontein is the first research performed in South Africa describing congenital heart defects in children with cleft lips and/or palates. The UAH provides plastic and reconstructive surgical care to the people in central South Africa, which mainly includes the Free State Province with an estimated population of 2.86 million. ${ }^{2}$

Hospitals and clinics from two neighbouring provinces (Eastern Cape and Northern Cape) also refer some patients to the UAH for tertiary care. Approximately $81 \%$ of the South African population is Black, $9 \%$ mixed race and $8 \%$ White, ${ }^{2}$ which is representative of the demographic profile of the Free State Province.

\section{Risk factors}

Various risks for cleft lip and/or cleft palate have been identified. These may be genetic, environmental exposure (maternal smoking, alcohol and phenytoin), parental age ( $>30$ years), or an interplay between these factors. ${ }^{1,3}$ In Middle Eastern populations, consanguineous marriage plays a role in the high prevalence of cleft anomalies. A recurrence rate as high as $5 \%$ in siblings suggests a polygenic hereditary risk factor. ${ }^{4}$ These factors were not examined in our study.

\section{Prevalence of clefts}

Cleft deformities are the most common craniofacial anomalies worldwide. ${ }^{3}$ Older international registries/data have shown the world-wide prevalence of cleft lips $(\mathrm{CL})$ to be 1 in 1000 live births. ${ }^{5}$ More recently, the United States National Birth Prevalence Network published the pooled prevalence of cleft lips (CL) and cleft palates (CP) to be 1 in 940 and 1 in 1574 live births, respectively. ${ }^{6}$ These figures can vary between investigators, race and countries studied. For example, cleft lips and/or cleft palates occur more frequently in Asians (1:500) than Caucasians (1:1000), and has the lowest prevalence in Africans (1:2500). ${ }^{3}$

\section{Gender}

There are variations in the reported gender ratios. Females are twice as likely to have a $\mathrm{CP}$, while males are twice as likely to have a CL/P. Males tend to have more severe disease. ${ }^{3}$ There was no statistically significant association between the various clefts and gender or race in our study.

\section{Clefts and syndromes}

International statistics published by the World Health Organization (WHO) reported that up to $50 \%$ of patients with an isolated $\mathrm{CP}$ have an associated congenital malformation. In contrast, $5-10 \%$ of patients with a CL/P have an associated congenital anomaly. ${ }^{1}$ In up to $30 \%$ of patients, clefting occurs 
Table III. Associated anomalies per type of cleft deformity

\begin{tabular}{|c|c|c|c|c|}
\hline & \multicolumn{3}{|c|}{ Type of cleft deformity } & \multirow{2}{*}{ Total $(n=62)$} \\
\hline & $C L(n=14)$ & $\operatorname{CLP}(n=25)$ & $C P(n=23)$ & \\
\hline Number of patients with cardiac defects: $n(\%)(p=0.44)$ & $5(35.7)$ & $7(28.0)$ & $4(17.4)$ & $16^{\mathrm{a}}(30.7)$ \\
\hline \multicolumn{5}{|l|}{ Type of cardiac defect } \\
\hline Ventricular septal defect (VSD) & 1 & 2 & 0 & 3 \\
\hline Patent ductus arteriosus (PDA) & 0 & 0 & 0 & 0 \\
\hline Patent foreman ovale (PFO) & 4 & 2 & 2 & 8 \\
\hline Atrial septal defect (ASD) & 1 & 1 & 0 & 2 \\
\hline Atrioventricular septal defect (AVSD) & 0 & 0 & 0 & 0 \\
\hline Pulmonary hypertension (PHPT) & 1 & 3 & 3 & 7 \\
\hline Peripheral pulmonary stenosis & 2 & 1 & 2 & 5 \\
\hline $\begin{array}{l}\text { Bicuspid aortic valve and azygous continuation of inferior } \\
\text { vena cava }\end{array}$ & 0 & 1 & 0 & 1 \\
\hline Enlarged right atrium & 0 & 1 & 0 & 1 \\
\hline $\begin{array}{l}\text { Aneurysmal intra-atrial septum with tricuspid insufficiency } \\
\text { and pulmonary incompetence }\end{array}$ & 0 & 1 & 0 & 1 \\
\hline $\begin{array}{l}\text { Number of patients with dysmorphism: } \\
n(\%)(p=0.03)\end{array}$ & $8(57.1)$ & $5(20.0)$ & $5(21.7)$ & $18(29.0)$ \\
\hline $\begin{array}{l}\text { Number of patients with syndromes: } \\
n(\%)(p=0.1)\end{array}$ & $2(14.3)$ & $0(0)$ & $2(8.7)$ & $4(6.5)$ \\
\hline
\end{tabular}

a Some patients had more than one clinically significant cardiac lesion.

as part of a syndrome. By implication, therefore, $70 \%$ of patients with clefts do not have a syndrome. ${ }^{1}$ Approximately 150 different syndromes have been associated with clefting, including Pierre Robin sequence, Treacher-Collins syndrome, Goldenhaar syndrome, with all of these presenting with airway difficulties. ${ }^{3}$ Considerable variation in the prevalence of $\mathrm{CL} / \mathrm{P}$-related syndromes has been reported, ${ }^{3}$ showing that a congenital malformation is found in $28-47 \%$ of patients with CP, $28-37 \%$ of patients with $C L / P$, and $8-13 \%$ of patients with $C L$. In the present study eighteen patients had dysmorphic features, which were not part of a syndrome. However, there was no statistically significant relationship between dysmorphism and congenital heart lesions.

\section{Clefts and congenital heart defects (CHD)}

The most common congenital malformation associated with cleft deformities is a congenital heart defect. ${ }^{4,7}$ Of the four patients who had a syndrome, three had an associated congenital heart defect confirmed on echocardiography, while the most commonly diagnosed cardiac lesions were PFO, VSD and ASD, which is consistent with previously published reports. ${ }^{4}$ Patients with clefts may have up to a 16 -fold greater incidence (up to $51 \%$ ) of cardiovascular malformation than the general population (6-8\%). These cardiac defects may be missed.7-10 Congenital cardiovascular malformations may involve the septa, central vasculature and cardiac valves. ${ }^{11}$ The association between clefts and CHD is not surprising, as similar insults may affect both the heart and the face which develop at similar times embryologically. ${ }^{3}$

According to a collaboration of 15 registries, $\mathrm{CL}$ is associated with congenital heart defects in $28.6 \%$ of cases, while $31.3 \%$ of cases with CP were associated with congenital heart defects. In Jordan, where consanguineous marriages are not uncommon, $47 \%$ of clefts are associated with CHD. ${ }^{4}$ A Nigerian study reported a prevalence of $20 \%$ of CHDs in patients with clefts. ${ }^{12}$ According to the authors' knowledge, there are no published figures for the prevalence of CHDs associated with oral clefts in South Africa.

\section{Clefts, CHD and anaesthesia}

According to patient history and physical examination, nine patients were flagged as possibly having a congenital heart defect. One of these patients had a non-clinically significant heart lesion. Of note, eight patients who had no clinical evidence of heart lesions were found to have clinically significant lesions on transthoracic echocardiography, which may have important anaesthetic considerations. The missed cardiac lesions in our study are notable. Some countries recommend transthoracic echocardiography in all patients with cleft deformities, as cardiac murmur is only $79 \%$ sensitive for detecting structural cardiovascular disease in these patients. ${ }^{4,8,11}$ Despite the 16 patients diagnosed with heart lesions, only two patients shunted intraoperatively during this three-year period. We postulate that this could be due to altered anaesthetic management because the anaesthesia team had preoperative transthoracic echocardiography results available before execution of the procedure.

Many considerations have to be taken into account when anaesthetising patients with clefts. ${ }^{3}$ Although a cardiac murmur is $97 \%$ specific as a sign of structural heart disease, auscultation has been found to be only $79 \%$ sensitive for picking up these lesions. ${ }^{11}$ Due to the high prevalence of congenital cardiac 
defects associated with clefts, routine echocardiography prior to surgery has been suggested. ${ }^{4}$

In the absence of an associated syndrome, cardiac or renal pathology, anaesthesia for routine cleft surgery is usually uncomplicated. $^{3}$ It is noteworthy that most patients with clefts and a cardiovascular malformation do not experience an increased intraoperative complication rate or require cardiac surgery to correct their cardiac defect. ${ }^{11}$

Historically, Kilner's rule of 10 (prerequisites for cleft lip surgery: age 10 weeks, weight $10 \mathrm{lb}$ and haemoglobin $10 \mathrm{~g} / \mathrm{dL}$; for cleft palate surgery: age 10 months, weight $10 \mathrm{~kg}$ and haemoglobin $10 \mathrm{~g} / \mathrm{dL}$ ) was applied to plan cleft surgery timing. ${ }^{13}$ However, international practice trends have shifted to operate on children with clefts at an earlier age to prevent developmental delays and improve aesthetics, parental bonding and feeding benefits. ${ }^{3,13}$ Certain cardiac defects can correct with age and without surgery, for example patent foramen ovale (PFO) and PDA. It has been advocated before that cleft lips should be operated by ten weeks of age. ${ }^{13}$ The youngest patient in our study was 22 weeks old, which is not in keeping with this guideline. Following the 10-month rule for cleft palate repair, ${ }^{13}$ it is evident that only 12 patients (19.4\%) were operated within this time period. Should the surgery have been performed earlier, we might have detected more congenital heart lesions that possibly could have closed by the age of surgery. This could be an explanation why in this study sample, we found that only $25.8 \%$ of children with clefts had congenital heart defects, compared with $50 \%$ noted in Jordan, where echocardiography is performed at birth. ${ }^{4}$ We postulate that should surgery be performed at a younger age, before physiological closure of defects, a higher prevalence of clinically significant cardiac defects may be found, which could impact anaesthesia.

High rates of consanguineous marriages in Jordan may further contribute to the high prevalence of clefts with associated cardiac defects, ${ }^{4}$ similar to findings reported from Pakistan. ${ }^{7}$ Compared to North Africa and the Middle East, consanguineous marriages are less common in South Africa. In total, consanguinity occurs in less than $10 \%$ of marriages in South Africa. ${ }^{14}$ The incidence of consanguineous marriages among black South Africans has been reported as ranging between $6 \%{ }^{15}$ and $22 \% .^{16}$ In 1966, Stevenson et al. ${ }^{17}$ reported the rate of consanguinity in South Africa as $0.7 \%$ among individuals of mixed ethnicity, $6.1 \%$ of Africans and $0.4 \%$ of the general obstetric population.

\section{National data and registries}

Birth defects result in significant infant morbidity and mortality. Various countries are attempting to improve birth defect surveillance and reporting by engaging in national databases and incorporating this data into an international registry. Limited epidemiological data are available for cleft lips and/or cleft palates in sub-Saharan Africa. ${ }^{18}$ In 2001, the South African National Department of Health issued a Policy Guideline for the Management and Prevention of Genetic Disorders, Birth Defects and Disability. This policy stated that cleft lips and/or palates be listed as one of six priority conditions for monitoring (registering and notifiable). ${ }^{18}$ Furthermore in 2001, the WHO made the recommendation that each country develops a national database for orofacial clefting. The WHO specifically mentioned South Africa, recommending that the database accurately records subtypes of clefts, whether there is an associated congenital malformation, or associated syndrome. They also proposed that the data be collected according to ethnic group, in an attempt to identify high-risk population groups. There was no statistically significant association between the various clefts and ethnic groups in the study, as stated before. It was further recommended that late-diagnosed cases be recorded. ${ }^{1,18}$ However, fifteen years later, this goal has not been achieved.

The authors acknowledge the limitations of this study. Inconsistencies in understanding the definitions of cleft lips and/or cleft palates may have influenced the review of data. However, the principal researcher (WJB) has been involved with the hospital's Smile Week since 2012, and performed the preoperative assessments of all the patients in this period. Arguably this may have caused bias, although the authors believe that it reduced methodological errors and maintained consistency in reporting.

The study population only included patients operated during the Smile Week. The Smile Week is held during the first week of September, which coincides with the beginning of spring. Many children suffer allergic rhinitis in springtime in our region, which might have resulted in patients'surgery being cancelled. It is also important to recognise that patients with VSDs and other high pulmonary flow cardiac lesions are predisposed to recurrent chest infections, and surgery might have been cancelled due to respiratory symptoms, excluding such patients from the study.

Due to the rural and remote nature of our region, and also the poor referral system, some patients with cleft deformities may not be referred to tertiary centres. Others may choose not to have surgery.

\section{Conclusions}

Our findings are the first published data from the Free State Province (central region) in South Africa, describing congenital heart defects in patients with cleft lips and/or palates. This association has important implications with regard to anaesthesia. Although history and careful clinical examination remain the cornerstone of patient care, the sensitivity of clinical examination to exclude cardiac defects is low. Consequently, preoperative echocardiography is recommended. The same considerations should be applicable for cleft patients requiring non-cleft surgery, even in cases where the cleft had been repaired previously.

The results of this study may be used as the basis for a national prospective multicentre study, including the eight South African academic institutions participating in the Smile Week. We suggest a national registry for patients with cleft lips and/or cleft palates with associated congenital anomalies in accordance 
with the WHO recommendations. ${ }^{1,18}$ It is also recommended that South Africa should develop a national guideline for the preoperative care of patients with cleft lips and/or cleft palates, with inclusion of routine preoperative echocardiography.

\section{Acknowledgements}

Dr Daleen Struwig, medical writer/editor, Faculty of Health Sciences, University of the Free State, for technical and editorial preparation of the manuscript.

\section{Disclosure statement}

The authors have no potential conflict of interest to report.

\section{ORCID}

\section{JDiedericks (D) https://orcid.org/0000-0003-2543-2996 CL Barrett (D) https://orcid.org/0000-0001-7700-8893}

\section{References}

1. Mossey P, Castilla E (editors). Global Registry and Database on Craniofacial Anomalies. Report of a WHO Registry Meeting on Craniofacial Anomalies, Bauru, Brazil, 4-6 December 2001. Geneva, Switzerland: Human Genetics Program, World Health Organization, 2003. Available from: www.who.int/genomics/ anomalies/en/CFA-RegistryMeeting-2001.pdf

2. Statistics South Africa. Statistical release P0302: mid-year population estimates 2016. Available from: https://www.statssa.gov.za/publications/P0302/ P03022016.pdf

3. Bösenberg AT. Anaesthesia for cleft lip and palate surgery. S Afr J Anaesth Analg 2007;13(5):9-14. Available from: http://www.sajaa.co.za/index.php/sajaa/article/ view/247

4. Aqrabawi HE. Facial cleft and associated anomalies: incidence among infants at a Jordanian medical centre. East Mediterr Health J 2008;14(2):356-359. Available from: https://www.ncbi.nih.gov/pubmed/18561727

5. Shprintzen RJ, Siegel-Sadewitz, VL, Amato J, Goldberg RB. Anomalies associated with cleft lip, palate or both. Am J Med Genet 1985;20(4):585-595. http://dx.doi. org/10.1002/ajmg.1320200404
6. Parker SE, Mai CT, Canfield MA, et al. Updated National Birth Prevalence estimates for selected birth defects in the United States, 2004-2006. Birth Defects Res A Clin Mol Teratol 2010;88(12):1008-1016. http://dx.doi.org/10.1002/ bdra.20735

7. Shafi T, Khan MR, Atiq M. Congenital heart disease and associated malformations in children with cleft lip and palate in Pakistan. Br J Plast Surg 2003;56(2):106109. http://dx.doi.org/10.1016/S0007-1226(03)00044-4

8. Milerad J, Larson $\mathrm{O}$, Hagberg C, Ideberg M. Associated malformations in infants with cleft lip and palate. A prospective, population based study. Pediatrics 1997;100(2 Pt 1):180-786. http://dx.doi.org/10.1542/peds.100.2.180

9. Taylor $M$, Persad $C$, Jones $C$. Undiagnosed cardiac defect in a patient with cleft lip and palate. Pediatr Anesth 2007;17(7):705-706. http://dx.doi. org/10.1111/j.1460-9592.2006.02189.x

10. Shah CV, Pruzansky S, Harris WS. Cardiac malformations with facial clefts; with observations on the Pierre Robin syndrome. Am J Dis Child 1970;119(3):238-244. http://dx.doi.org/10.1001/archpedi.1970.02100050240010

11. Harry BL, TeBockhorst S, Deleyiannis FW. The impact of congenital cardiovascular malformations on the assessment and surgical management of infants with cleft lip and/or palate. Cleft Palate Craniofac J 2013;50(3):323-329. http://dx.doi. org/10.1597/12-131

12. Asani MO, Aliyu I. Pattern of congenital heart defects among children with orofacial clefts in Northern Nigeria. J Cleft Lip Palate Craniofac Anomal 2014;1(2):85-87. http://dx.doi.org/10.4103/2348-2125.137895

13. Bösenberg AT, Kimble FW. Infraorbital nerve block in neonates for cleft lip repair: anatomical study and clinical application. Br J Anaesth 1995;74(5):506-508 http://dx.doi.org/10.1093/bja/74.5.506

14. Bener A, Mohammad RR. Global distribution of consanguinity and their impact on complex diseases: genetic disorders from an endogamous population. Egypt J Med Hum Genet 2017;18(4):315-320. http://dx.doi.org/10.1016/j. ejmhg.2017.01.002

15. Bittles AH, Black ML. Consanguineous marriage and human evolution. Ann Rev Anthropol 2010;39(1):193-207. http://dx.doi.org/10.1146/annurev. anthro.012809.105051

16. Leutenegger AL, Sahbatou M, Gazal S, Cann H, Génin E. Consanguinity around the world: what do the genomic data of the HGDP-CEPH diversity panel tell us? Eur J Hum Genet 2011;19(5):583-587. http://dx.doi.org/10.1038/ejhg.2010.205

17. Stevenson AC, Johnston HA, Stewart MI, Golding DR. Congenital malformations. A report of a study of series of consecutive births in 24 centres. Bull World Health Organ 1966; 34 (suppl): 9-127. Available from: https://www.ncbi.nlm.nih.gov/ pmc/issues/169265/

18. South African Department of Health. Human genetics policy guidelines for the management and prevention of genetic disorders, birth defects and disabilities. 2001. Available from: http://www.gov.za/sites/www.gov.za/files/ humangenetics_0.pdf 